Dariusz Lipiec

John Paul II Catholic University of Lublin, Poland

\title{
Rezension: \\ Wiesław Przygoda, Apostolski wymiar wolontariatu charytatywnego w Polsce. Studium teologiczno-pastoralne na podstawie badań wolontariuszy z parafialnych zespołów Caritas, Lublin 2012
}

(Apostolische Dimension des karitativen Volontariats in Polen. Pastoraltheologische Studie über die Volontärarbeit in „Caritas“ - Pfarreigruppen, Lublin 2012, Towarzystwo Naukowe, 451 Seiten, ISBN 978-83-7306-573-4)

Unter Volontariat versteht man den Dienst an bedürftigen Personen und gesellschaftlichen Gruppen. Freiwilligkeit, Selbstlosigkeit und Planmäßigkeit sind prägende Eigenschaften dieses Phänomens, das den Charakter einer organisierten sozialen Bewegung aufweist. Die Idee des Volontariats entspringt der Überzeugung, dass aktuelle soziale Wandlungen in erster Linie nicht den Widerstands gegen das Böse, die Destruktion nach sich ziehen können, sondern des positiven Engagements bedürfen, um das Gute $\mathrm{zu}$ verwirklichen.

Christliches Volontariat stützt sich auf das Gebot der Gottes- und Nächstenliebe, das den Grundsatz des christlichen Lebens und des Lebens der Kirche als einer christlichen Gemeinde bildet. Die Tätigkeit der Volontäre in kirchlichen Gruppen gewinnt daher apostolische Dimension, da der Dienst der Kirche einen ihrer Natur und Botschaft entsprechenden Missionscharakter hat ${ }^{1}$.

Ibidem S. 908; Vgl. M. Puzewicz, Chrześcijański wolontariat, in: Komisja Duszpasterstwa Ogólnego Konferencji Episkopatu Polski (Kommission für Allgemeine Seelsorge des Episkopats Polens), Gtosić Ewangelię nadziei. Program duszpasterski na rok 2004/2005, Katowice 2004, S. 264-266. 
Das Volontariat wurde zum Thema mehrerer Veröffentlichungen sowohl im Ausland als auch im Inland. Die apostolische Dimension des katholischen Volontariats wurde jedoch - nicht nur in Polen - kaum aufgegriffen. Vor kurzem erschien die lange erwartete Studie von Wiesław Przygoda, dem Leiter des Lehrstuhls für Karitative Theologie an der Katholischen Universität Johannes Paul II. in Lublin, unter dem Titel: Apostolski wymiar wolontariatu charytatywnego $w$ Polsce. Studium teologiczno-pastoralne na podstawie badań wolontariuszy z parafialnych zespołów Caritas.

Das angesprochene wissenschaftliche Problem wurde von W. Przygoda in fünf Kapiteln erörtert. Im ersten Kapitel wurden das Wesen des Volontariats und sein apostolischer Charakter besprochen, indem sowohl der historische Ursprung des Volontariats, als auch seine theologischen Grundlagen und zeitgenössischen kulturellen, sozialen und rechtlichen Voraussetzungen dargestellt wurden. Im zweiten Kapitel konzentrierte sich der Autor auf die Frage der apostolischen Dimension des Volontariats im Bewusstsein der untersuchten Personen. Im dritten Kapitel wurde die Zugehörigkeit der Befragten zu Gemeinschaftsstrukturen abgehandelt. Die Ergebnisse dieser Untersuchung führen zu dem Schluss, dass die in Caritas-Pfarreigruppen tätigen Volontäre die Kirche hauptsächlich als eine Gläubigengemeinschaft betrachten.

Das vierte Kapitel wurde der Umsetzung der apostolischen Aufgaben durch karitative Volontäre gewidmet. Aus den gewonnenen Ergebnissen kann man schließen, dass die Mehrheit der Befragten das Werk der Barmherzigkeit durch Bekanntmachungen der Pfarrei, direkte Gespräche mit Pfarreimitgliedern, Plakate, Anschläge und Informationen im Schaukasten der Pfarrei propagiert. Das fünfte und letzte Kapitel der Studie bezieht sich auf die apostolische Dimension der Geistigkeit der Volontäre und stellt u.a. die Motive für die Ausübung der Werke der Barmherzigkeit durch die Befragten dar.

Der wissenschaftliche Wert der Veröffentlichung besteht nicht zuletzt in einem umfangreichen Literaturverzeichnis (S. 339-360), das die jeweils betreffende Kirchenlehre, wie auch Fachliteratur und ergänzende Literatur umfasst. Die vom Autor erstellten Anhänge enthalten den in der Untersuchung angewandten Fragebogen, Dokumente der polnischen Kirche zu Caritas-Pfarreigruppen und Volontariat und - was besonders wichtig erscheint - Tabellen und Diagramme, die keinen Platz im Hauptteil der Arbeit gefunden haben, das Wissen der Leser über christliches Volontariat und seinen apostolischen Charakter jedoch erweitern können. 
Die Studie von W. Przygoda ist eine originelle und aufschlussreiche Arbeit. Die dazu notwendigen Erkenntnisse schöpfte er aus den durch die in Pfarreigruppen engagierten Volontäre ausgefüllten Fragebögen. Es ist hinzuzufügen, dass der Fragebogen von ihm selbst erstellt wurde. Die so gewonnenen Untersuchungsergebnisse erlauben Einblick in die von Volontären in den Pfarreien geleistete Arbeit, was die karitative Tätigkeit der Kirche in einem neuen Licht erscheinen lässt. Vorrangig kann jedoch dank der Studie von W. Przygoda die apostolische Dimension des christlichen Volontariats als ein wesentlicher Aspekt der Mission der katholischen Laien in der Welt mit der gebührenden Aufmerksamkeit wahrgenommen werden.

Der Autor beschränkt sich nicht auf die Wiedergabe der Untersuchungsergebnisse, sondern führt ihre Analyse in Bezug auf die Lehre der allgemeinen Kirche und der Kirche in Polen durch. Die daraus gezogenen Schlüsse und pastoralen Postulate richten sich sowohl an die Volontäre selbst als auch an Geistliche, die ihre Arbeit leiten und koordinieren. Sie wurden im ausführlichen Schlusskapitel (S. 307-337) dargestellt - diese Vorgehensweise erlaubt es, die Arbeit von W. Przygoda durchaus als pastoraltheologische Studie zu bezeichnen.

Das Buch Apostolski wymiar wolontariatu charytatywnego w Polsce. Studium teologiczno-pastoralne na podstawie badań wolontariuszy z parafialnych zespołów Caritas kann man als eine unter vielen Aspekten - sowohl in Bezug auf seinen Inhalt als auch seine Form - reife Arbeit betrachten. Aus diesem Grund kann es breite Anwendung in der Pastoralarbeit und als didaktisches Mittel finden. Besonders nützlich scheint es für diejenigen zu sein, die die karitative Arbeit der Kirche auf allen Stufen: sei es in der Pfarrei, Diözese oder im ganzen Land, leiten. Das im Buch vermittelte Wissen kann bei der Planung der weiteren Caritas- Arbeit und bei der Bildungsarbeit für Volontäre sehr hilfreich sein. Es ist aber auch für Theoretiker zu empfehlen, denn die in der Studie aufgegriffenen Fragen aus dem Bereich des christlichen Volontariats bedürfen oft weiterer Forschungen. Auch für Studenten solcher Fachrichtungen wie Sozialarbeit, Theologie, Pädagogik und Soziologie wäre es empfehlenswert, sich mit dieser Studie vertraut zu machen. Fragen, mit denen sie sich bereits beschäftigt haben, erscheinen dann in völlig neuem Licht. 